which points the ice had either all volatilised or had become detached from the bulb. This appears improbable from our present ideas concerning latent heat, but it is nevertheless a fact. If I can make the necessary arrangements it is my intention to show the experiment at an early meeting of the Chemical Society, when it will be open to criticism.

In regard to the remarks contained in the former part of $\mathrm{Mr}$. Hannay's letter, I of course did not bring forward the first proposition in my letter as anything new, but merely to show that my experiments confirmed the previous conclusions of other on the critical temperature.

Firth College, Sheffield, September 27

\section{A Peat Bed in the Drift of Oldham}

IN NATURE, vol. xxii. p. 460 , there is a description of a bed, or rather beds, of peat in the drift at Oldham. A few days ago I had an opportunity of examining the section described by Mr. Jas. Nield, and under his guidance, but I differ from him in opinion as to the age of the peat. The section occurs on the steep sloping side of a valley, and just above it there is an exposure of sand covered by boulder clay. In my opinion some of the latter has simply slipped down, off the sand, on to the surface of the peat at a lower level; or it may have been excavated and thrown down for the purpose of obtaining the underlying sand. Besides, the principal bed of peat rests on blue silt, which again rests on boulder clay. The upper bed of peat occurs at one end of the section, and both ends present the appearance of a talus of debris from a higher level. Still the section is somewhat obscure, though a few hours' digging at a right-angle to its present exposure would probably prove the blue silt and peat to be more recent than the boulder clay, although the latter is certainly the highest bed in the section as at present exposed. However, geologists are indebted to Mr. Nield for calling attention to the section, and no doubt he and others will take means to prove the true position of the peat, which is sure to attract considerable attention.

122, London Road, Liverpool, September 18

G. H. MORTON

\section{Hardening of Steel}

I SHOULD have, had circumstances permitted, thanked $\mathrm{Mr}$. Walter R. Brown for his kind response to my letter, "Iron and Hydrogen" (NATURE, vol. xxij. p. 220), and for the reference to Mr. Anderson's report, with which I was unacquainted.

The points mentioned by Mr. T. W. Giltay certainly seem somewhat to controvert the theory of alloyed hydrogen; but thinking over the facts some time ago it struck me that the aqueous vapour in the air would be a source for the gas as in chilling beneath water. It would be interesting to know whether mercury, as commonly used, is not also faintly alloyed with hydrogen.

For my own part, I am inclined to the carbon theory, but the facts were brought forward with the idea of seeing them discussed, and a somewhat obscure but important subject brought to light. H. J. JohNSTON-LAVIS

\section{Mosquitos}

SEEING in NATURE, vol. xxii. p. $\mathrm{I}$, the use of infusion of quassia recommended, and being a great martyr to mosquitos, I immediately set to work to brew two or three gallons with all the energy with which I had already tried many remedies and nostrums.

The basements of nearly all the good houses here in Naples are used as stables, and consequently form a great attraction for these insect pests.

This large quantity of very concentrated infusion was disposed of as follows:- The whole of the bed-room walls, ceiling, carpet, and furniture were gone over with a Lister's vapour carboliser containing the solution; sheets and night-dresses wrung out and dried before use, body sponged all over, and bed clothes re-sprayed with the solution each night.

This certainly was a fair trial, but the results after all this expense, trouble, bitter lips and mouth was a complete failure.

It really seems that the only true protection against mosquito is the curtain with all its inconveniences.

September 21

H. J. JohNSTON-LAvis

\section{GENERAL PITT RIVERS' (LANE FOX) ANTHROPOLOGICAL COLLECTION ${ }^{1}$}

\section{II.}

UTRIGGERS are very varied in their structure. In some canoes there are two opposite one another, of which does not touch the water; it is merely a balance platform; in some both outriggers only occasionally touch the water. It is not improbable that the sidegalleries of some junks are developed out of balance platforms, and that the ledges known as the "chains" of modern European vessels are of similar origin. The rudder is merely a development of the steering paddle. It is still merely a fixed paddle, being worked by an operator with his face in the direction in which the boat is moving, whilst oars have taken the place of all the other paddles of the boat.

Another series illustrates the origin of clothing. Clothing wâs derived, no doubt, partly from the development of ornaments, being originally entirely ornamental, as a large proportion of it still is, even amongst ourselves, and partly from gradual modifications of belts and such accoutrements, which served a useful purpose when put round the body as convenient appliances for hanging things to for carriage. A pocket is a luxury which a savage does not possess. He has to sling his little necessaries to his belt, or secure them in the lobe of his ear, or carry them, to his embarrassment, in his hand. Even in Japan the men are obliged to sling their tobaccopouches and pipes from their belts by means of silken cords and the beautifully-carved ivory buttons or netsukes so well known in European collections. They have pockets only in their sleeves, and these are insufficient. The simple cincture is the sole clothing of the Andaman Islander. A bunch of pandanus slips is added in front in a further stage, and eventually a complete encircling fringe is reached. When paper cloth (tappa) has been invented, or woven material, this is substituted for the fringe, and a kilt is the result. In some parts of Great Britain dress has not advanced beyond this stage, or rather the primitive form of dress has been adopted as a curiosity. The sporran probably represents the original dress, the bunch of grass of the Andaman Islander, now worn over the kilt instead of as originally next the skin. At a further stage, the kilt being found uncomfortable, it was fastened together at one spot between the legs, and hence arose the idea of trousers, which, through the baggy Turkish inexpressibles, gradually developed into their present form.

The simple cloak of skin or tappa developed gradually into coats and various more convenient tight-fitting garments, but in all robes of ceremony the savage cloak form is still retained by the most highly civilised races. One of the latest additions made to his collection by General Pitt Rivers is a series of Britanny caps, showing the gradual development of all the strange forms in vogue in different districts, by means of the abnormal growth of the strings, crown, or front, of one simple type.

Another series shows the development of drinkingvessels of all kinds, starting from the natural vessels found ready to hand, such as human skulls, cocoanutshells, gourds, and horns. From the cocoanut with a handle comes the ladle, and hence the spoon, and so on.

Another series is devoted to the development of musical instruments. Wind instruments are modifications derived from the horns of animals, spiral shells, reeds, bamboos, and bones. From these by gradual steps are attained the trumpet and spiral brass instruments, the curl of which probably came from the spiral shell; also panpipes, and hence organs, and flutes. As bearing on the origin of the bagpipes is exhibited a bag and whistle carried by Indians of the north-west coast of America to imitate the call of ducks and decoy them.

$$
\text { I Continued from p. } 493 .
$$


Drums were derived from bamboos, being at first simple pieces of bamboo open at both ends and beat on the ground as now at Fiji. Wooden logs are then hollowed out to imitate them, and hence the large erect wooden drums of New Guinea and Melanesia generally, and the horizontal canoe-like drums, "lali," of Fiji. But these hollow wooden drums without a tense membrane are more justly classed with bells, and metal

Fig.1.

Fig.e.

Fig. 3.
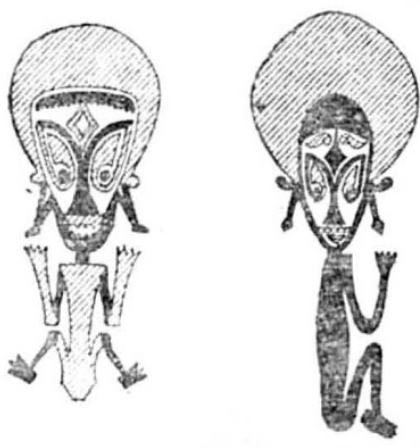

Fig.6.
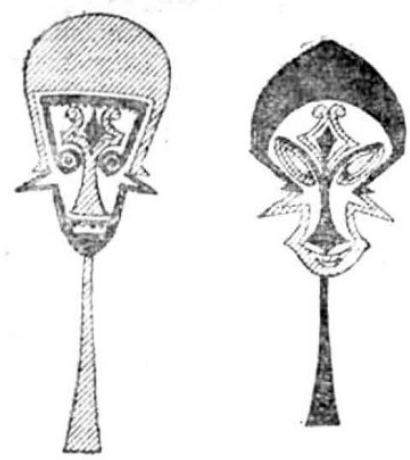

Fig. 7.

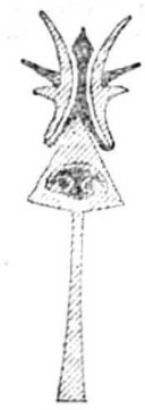

Fig.10
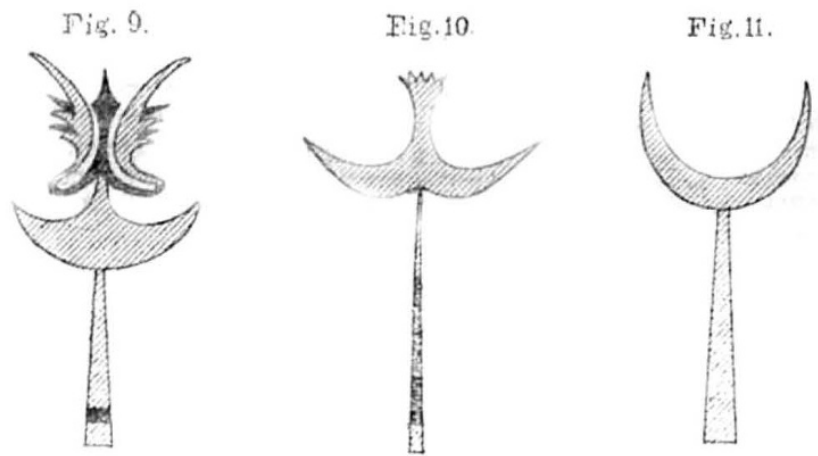

PlATE 3.-Omamentations copied from a series of canoe paddles from New Ireland, showing the gradual clegeneration $f$ the representation of the human form into a crescent-shaped cruament.

bells were probably derived from them through the wooden bells stich as those used in Japan. The clapper is a late addition to the bell, which does not exist in Japan or China. It is worthy of note that the large wooden drums of Fiji and Papua are used for the same purpose as bells, to summon large meetings and communicate general warnings or similar intelligence. Dr. Michlucho Maclay has given a full account of their use in New Guinea. in dancing.

A tense membrane having been added to one end of a bamboo, the real drum was reached, and from this is derived the Papuan drum, which is long and pipe-like in form, and has a membrane of lizard skin (Hydrosaurus) at one end. It is often shaped like a crocodile's head at the open end, is somewhat dice-box-shaped, and is used

Another series is devoted to the growth of the art of pottery. Amongst savages the Fijians are

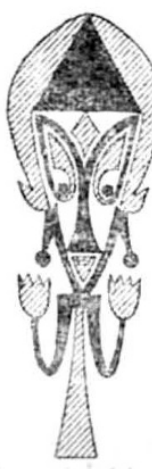

Fig. 8.

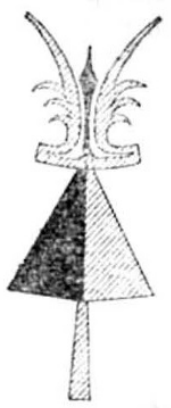

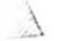

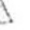

carved by the Vancouver Islanders. They are very different indeed in execution, and rude, but they still show a certain amount of artistic feeling. Indeed, the whole of the Indians of the Upper 'North-West Pacific coast, and especially the Haidahs, are conspicuous for very advanced artistic powers as savages. Savages vary immensely in their artistic development. Many, such as the Hottentots and South African races generally, appear never to have made any representations of the human figure. Those who do make such figures always adopt a conventional form for them, which is so well marked that an experienced eye can detect at once by what race any particular figure has been made. Perhaps the most curious figures are those of Easter Island, with shrunken abdomens and prominent ribs. The figures seem copied from half dried-up corpses, and were perhaps copied from the dead originally. Some Peruvian human faces are extremely good; but the Japanese and Chinese seem never to have idealised the human countenance, except perhaps in their representations of Buddhist gods, the faces of which are however more or less Indian in type, so that the idea was probably derived, with the religion, from extraneous sources.

A considerable series is devoted to the development of religious properties of various kinds from different parts of 
the world. Side by side are placed the coarse wax models of breasts, hands, feet, eyes, and other parts of the human body offered up at the present time in Roman Catholic shrines in France and elsewhere by persons who have been cured of diseases in those parts, and the exactly similar earthenware models of the same parts which were used for the same purpose in ancient Cyprus, and have been found there in excavations. It is most curious how exactly the two series correspond. A small collection comprehends the representations of the Mother and Child of various races. Side by side may be seen and compared the Peruvian, Cyprian, Egyptian, Indian, Chinese, and Christian embodiments of this idea.

Several series are devoted to the curious question of the development of pattern ornament. The development of patterns appears to have arisen in two ways : either drawings of various natural objects have been made upon weapons, implements, and utensils, and these drawings, having become more and more conventionalised by succes- sive copyings, have degenerated into patterns which have in many instances been subsequently elaborated as such ; or various patterns have been. from the first suggested by various articles often used in connection with the objects ornamented, by coils of string, or by wire, or by nets, or accidental markings on the objects themselves. Patterns thus once commenced have been gradually modified, and have run through a series of changes which can be traced step by step. A particular elaborate pattern is a thing which has probably arisen only once in the progress of evolution, and in tracing its history we trace at the same time the history of the race which makes use of it. It may yield as important evidence as even language itself.

The earliest known ornamentations are those of primitive man found in the caves of Europe. They are all representations of animals, figures of the mammoth, cavebear, or reindeer scratched on ivory or bone. Some of the most interesting of General Pitt Rivers' series are those which show how such rude figures gradually de-
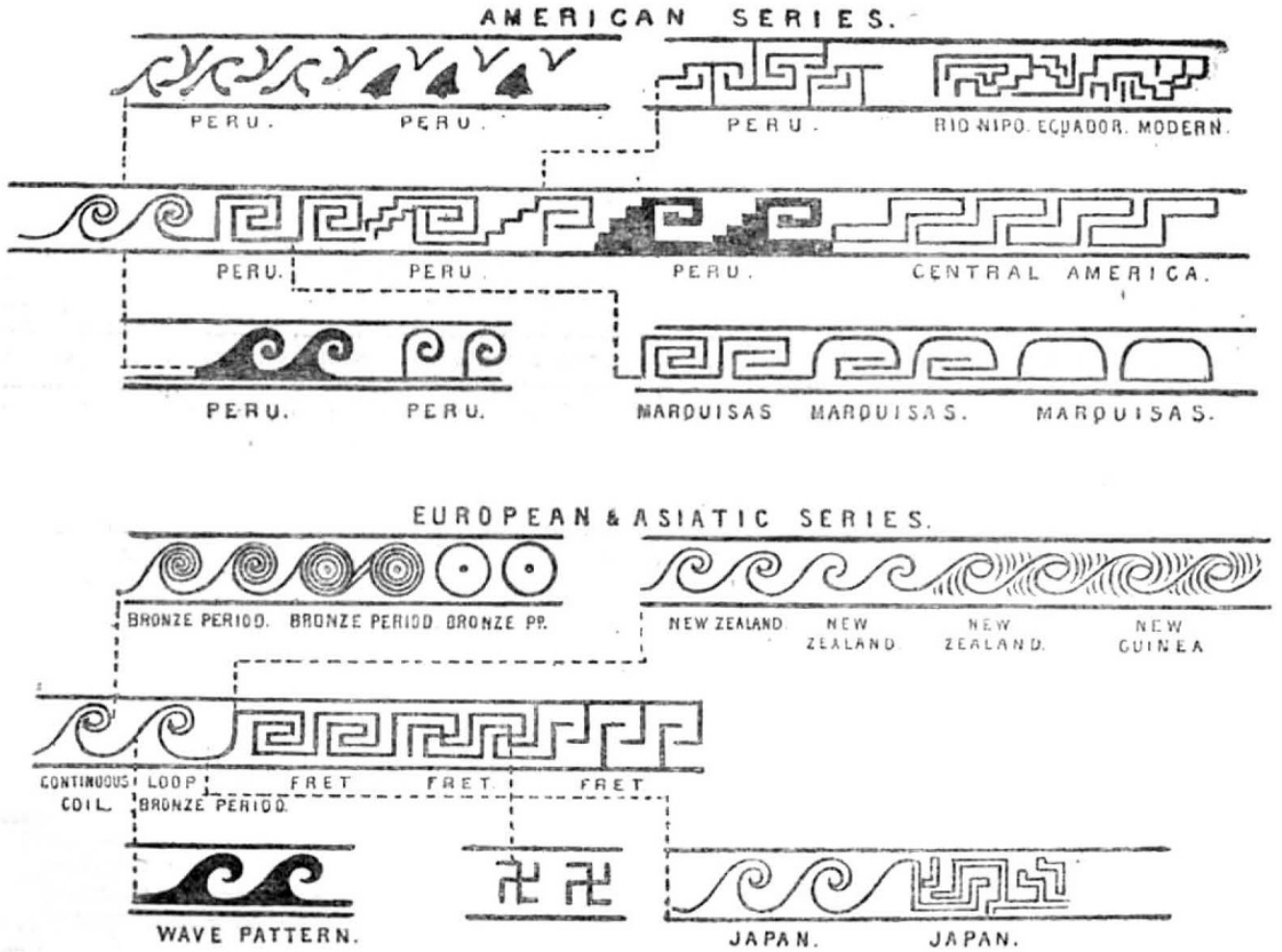

PLATE 4.-Series of diagrams to illustrate the various modifications of the double loop coil ornament in the Old and New Worlds.

generate into mere conventional pattern ornaments. One of the most striking examples is one described by him in his address to the Department of Anthropology at the meeting of the British Association at Brighton in 1872 , It is the series of transformations which are undergone by a figure of a human head represented on their paddles by the natives of New Ireland. The series is shown in the annexed woodcut (Plate 3 ), taken from the specimens exhibited in the collection. The human figure gradually loses its limbs and body, then the sides of the face, leaving only the nose and ears, and ultimately the nose only, which finally expands at the base, and is converted into the representation of a half moon. In this sequence we have an exact parallel to the transformations observed upon ancient British coins by Mr. John Evans, by which the representation of the chariot and horses of Victory on a coin of Philip of Macedon becomes converted into a single horse, and ultimately into fragments of a horse.

Amongst the natives of the North-West coast of America a curious intricate conventional ornament represented on all their paddles and many other objects, is derived from an albatross head, as shown in a series in the collection. A series of curved wooden sharp-edged clubs or glaives show how the form of a fish, to represent which the curved head of the club is carved, degenerates into a single $W$ ornament, the remains of the fish's mouth. Mr. Brooke Low has in his Bornean collection already referred to a series of native fabrics ornamented with elaborate patterns, each of which pattern has a name, usually the name of an animal. One pattern is evidently a representation of a crocodile, it is so named, and others are derived from it. He finds it impossible to determine in many instances by examination from what form the other patterns have been derived; but believes that the history of their origin survives in their names. One name given to them was, for example, "cat," referring to the animal, from a drawing of which the pattern was originally developed. No doubt all the curious patterns in vogue 
in Polynesia, New Guinea, and elsewhere, have a definite history and meaning yet to be traced. Modern European patterns have also interesting histories to disclose. One of the series in the collection explains the origin of the lozenge- and leaf-pattern common on oak carvings from the intersections of the Gothic arch and ogee arch.

Of the development of ornament from chance marks upon objects, the most interesting example exhibited is probably an Australian boomerang, which happens to have three small round black knots on one side of it placed at equal intervals. The savage owner, struck by the appearance of the knots, burnt a series of similar black marks at equal distances all along the one face of the boomerang, to complete the natural pattern, and then, pleased with his work, put a series of lozenge-shaped marks to correspond on the other side of the weapon. At the Sandwich Islands a most beautiful ornament of the gourds used for water is derived from the net-bag in which the gourds were slung. No doubt the pattern at first became accidentally printed on the gourds, and were afterwards elaborated.

The last series to which we shall draw attention relates to the transformations of the curious ornament which General Pitt Rivers calls the double-loop coil, and which is characteristic of all New Zealand weapons and implements, canoes and houses. The ornament was probably originally copied from coils of string or wire. The distribution of the ornament is very interesting. It is found abundantly in New Guinea, so exactly corresponding to the New Zealand form that it seems certainly to point to some connection between the islanders or partial migration from New Guinea to New Zealand at some time or other, unless some floating object may have conveyed the pattern. A similar ornament occurs in the far-off Marquesas Islands, the natives of which in several other matters of culture show affinity with the Melanesians. It is also very common on Mexican and Peruvian works of art, and especially on gold figures, where it is represented in its former live form by spiral coils of fine wire. From the double-loop coil, as General Pitt Rivers has shown, many other patterns are derived. The fret or key pattern is merely a continuous loop-coil squared. Other patterns, such as the wave pattern, are derived from the coil by slight degeneration. Some of the most marked patterns derived from it are shown in the accompanying figure (Plate 4), which explains itself. It is most curious how nearly parallel the series of modifications attained in the Old and the New World run to one another.

In conclusion we can only express a hope that the Pitt Rivers collection will be accepted by the nation on its generous donor's conditions, and we strongly recommend any of our readers who have not studied it to pay it a long visit at once, and profit by the varied fund of instruction and entertainment which it cannot fail to impart.

\section{THE MASON COLLEGE, BIRMINGHAM}

THE Josiah Mason Science College, which is to be opened by an interesting address from Prof. Huxley to-morrow, was begun about five years ago by the venerable and generous donor, Sir Josiah Mason. It is intended to cover ground not occupied by any other of the numerous educational institutions of Birmingham, to which it promises to be an addition of the highest value. The building itself is described as a lofty and spacious Gothic pile, covering about an acre in extent in the very heart of Birmingham.

By its foundation deed the College is established to provide instruction, as far as possible, in mathematics, abstract and applied; physics, both mathematical and experimental; chemistry, theoretical, practical, and applied; the natural sciences, especially geology and mineralogy, with their application to mines and metal- lurgy; botany and zoology, with special application to manufactures; physiology, with special reference to the laws of health; the English, French, and German languages; and the scheme may, in the discretion of the trustees, include all such other branches of instruction as will conduce to a sound practical knowledge of scientific subjects, excluding mere literary education. The trustees have also power to make provision for instruction in art as well as in science; and, by a supplemental deed, they are authorised to include in the course of study certain subjects requisite for the training of medical students. There is no restriction of the advantages of the college as to sex, creed, or birthplace; but, other things being equal, preference is to be given to candidates who have been educated in Sir Josiah Mason's Orphanage at Erdington, and after these to persons born in Birmingham or Kidderminster, the latter being the founder's birthplace. One wise provision of the deed empowers the trustees, with certain reservations, to alter the course of teaching and the arrangements of the instruction when a change is considered desirable, and at stated intervals the trustees are required to take the arrangements into consideration with a view to revision. At present the branches for which provision is made are confined to mathematics, physics, chemistry, and biology. The mathematical professor is Mr. J. M. Hill, M.A., London, B A., Cantab, Fellow of University College, London. Physics are taught by Prof. J. H. Poynting, M.A., B.Sc., London, Fellow of Trinity College, Cambridge. The chemistry professor is Mr. W. A. Tilden, D.Sc., London, F.R.S.; and biology is represented by Prof. T. W. Bridge, M.A., F.Z.S. According to present arrangements instruction is provided in the elementary as well as the higher branches of the sciences taught, with a special view to their application to the industries of the Midland district. The course is also designed to prepare students for the degrees of B.Sc. and D.Sc. in the University of London.

The internal arrangements seem to be altogether admirable. The main corridor abuts on two noble apartments, each 48 feet by 30 feet - one intended for the library and reading-room, the other for the physical laboratory-both rooms being provided with ante-rooms. On the first floor, the chief and central room, situated in the front of the building, is the chemical lecture theatre, 50 feet by 33 feet, fitted with seats, tier above tier, for the accommodation of 155 students. The male students will occupy the lower half and the female students the seats above and behind them, a separate entrance being provided for each sex. The mechanical arrangements and apparatus for the use of the lecturer and the carrying away of noxious fumes are of the most complete and ingenious character, and the assistants' ante-room, for the preparation of chemical experiments, is on an equally satisfactory scale. Class-rooms for electricity, magnetism, biology, physics, and models, and a couple of spacious lecture theatres, each 47 feet by 30 feet, one for biology and mathematics, the other for physics, occupy the remaining space on the first floor. The second floor is devoted principally to the chemical departments, for which the arrangements are of the most complete and elaborate character. A large room, 52 feet by 33 feet, in the front of the building, over the chemical lecture theatre, will be used as a general assembly or examination room, and will be available for the meetings of scientific societies. The two laboratories situated at the back of the building, and lit both by windows and skylights, measure together about 104 feet long by 32 feet wide. In the larger laboratory, intended for qualitative analysis, there are four double operating-tables fitted with sinks, gas and water for forty students, in addition to a large unencumbered table in the middle of the apartment for long trains of chemical apparatus. The laboratory for quantitative analysis contains similar fittings and appliances 